Check for updates

Cite this: Chem. Sci., 2019, 10, 3627

๑ All publication charges for this article have been paid for by the Royal Society of Chemistry

Received 18th December 2018 Accepted 6th February 2019

DOI: $10.1039 / c 8 s c 05657 a$

rsc.li/chemical-science

\section{Synthesis of acyl(chloro)phosphines enabled by phosphinidene transfer $\dagger$}

\author{
Kevin M. Szkop, (D) ab Michael B. Geeson, (D) ${ }^{\mathrm{b}}$ Douglas W. Stephan (iD) *a \\ and Christopher C. Cummins (iD *b
}

\begin{abstract}
Acyl(chloro)phosphines $\mathrm{RC}(\mathrm{O}) \mathrm{P}(\mathrm{Cl})(t-\mathrm{Bu})$ have been prepared by formal insertion of tert-butyl phosphinidene $(t-\mathrm{Bu}-\mathrm{P})$ from $t$-BuPA $\left(\mathrm{A}=\mathrm{C}_{14} \mathrm{H}_{10}\right.$ or anthracene) into the $\mathrm{C}-\mathrm{Cl}$ bond of acyl chlorides. We show that the under-explored acyl(chloro)phosphine functional group provides an efficient method to prepare bis(acyl)phosphines, which are important precursors to compounds used industrially as radical polymerization initiators. Experimental and computational investigations into the mechanism of formation of acyl(chloro)phosphines by our synthetic method reveal a pathway in which chloride attacks a phosphonium intermediate and leads to the reductive loss of anthracene from the phosphorus center in a $\mathrm{P}(\mathrm{v})$ to $\mathrm{P}(\mathrm{III})$ process. The synthetic applicability of the acyl(chloro)phosphine functional group has been demonstrated by reduction to an acylphosphide anion, which can in turn be treated with an acyl chloride to furnish dissymmetric bis(acyl)phosphines.
\end{abstract}

Acylphosphines and their oxides are used as photoinitiators for radical-initiated polymerization ${ }^{\mathbf{1 - 4}}$ reactions used in the manufacture of consumer goods such as automotive coatings, adhesives, latex composition kits, and various dental and orthodontic materials. ${ }^{5-14}$ Known methodologies for the synthesis of acylphosphines employ nucleophilic sources of phosphorus such as tris(trimethylsilyl)phosphine (P(TMS) $)_{3}$, TMS = trimethylsilyl) ${ }^{15-17}$ which is volatile, pyrophoric, toxic, expensive, and difficult to handle. ${ }^{18}$ Transition metal-supported phosphines and phosphides have been used as a platform in niche syntheses of acylphosphines, though scope is limited and products remain bound to the metal center. ${ }^{19-23}$ Perhaps the most versatile synthetic approach has emerged from the groups of Liotta, Becker, Grützmacher and Mézailles who employ $\mathrm{PH}_{3}$ and $\mathrm{MPH}_{2}(\mathrm{M}=\mathrm{Li}, \mathrm{Na}, \mathrm{K})$ as nucleophilic sources of phosphorus en route to a wide variety of mono-, bis-, and tris(acyl) phosphines. ${ }^{24-31}$ More recently, salts of the 2-phosphaethynolate anion $\left([\mathrm{PCO}]^{-}\right)$have been used in the synthesis of functional groups related to acylphosphines. ${ }^{32}$ Despite these advances, enlarging the scope of methods for accessing valuable acylphosphines with different substitution patterns remains an attractive goal. ${ }^{33}$

${ }^{a}$ Department of Chemistry, University of Toronto, 80 St George St, Toronto, Ontario, M5S3H6, Canada. E-mail: dstephan@chem.utoronto.ca; Tel: +1 4169463294

${ }^{b}$ Department of Chemistry, Massachusetts Institute of Technology, 77 Massachusetts Avenue, Cambridge, MA 02139-4307, USA. E-mail: ccummins@mit.edu; Tel: +1617 2535332

$\dagger$ Electronic supplementary information (ESI) available. CCDC 1882890-1882892. For ESI and crystallographic data in CIF or other electronic format see DOI: $10.1039 / \mathrm{c} 8 \mathrm{sc} 05657 \mathrm{a}$
We have identified dibenzo- $7 \lambda^{3}$-phosphanorbornadienes (RPA, $\mathbf{A}=$ anthracene or $\mathrm{C}_{14} \mathrm{H}_{10}$ ) as efficient compounds to generate and transfer metastable singlet phosphinidene species. $^{\mathbf{3 4 , 3 5}}$ Herein, the tert-butyl phosphinidene group of $t$ BuPA is shown to formally insert into the carbon-chlorine bond of acyl chlorides to generate the rare acyl(chloro)phosphine functional group. ${ }^{36,37}$ This product is subsequently exploited for further functionalization.

Treatment of $t$-BuPA with benzoyl chloride $(\mathrm{PhC}(\mathrm{O}) \mathrm{Cl})$ in dichloromethane at $23{ }^{\circ} \mathrm{C}$ (Scheme 1) led to an instant colour change from colourless to bright yellow, and the quantitative formation of 1 as a yellow powder, isolated in $82 \%$ yield. The species exhibited a singlet resonance at $\delta 114 \mathrm{ppm}$ in the ${ }^{31} \mathrm{P}$ $\left\{{ }^{1} \mathrm{H}\right\}$ NMR spectrum. The ${ }^{13} \mathrm{C}\left\{{ }^{1} \mathrm{H}\right\}$ NMR spectrum of 1 shows a diagnostic doublet resonance in the carbonyl region at $\delta 210 \mathrm{ppm}\left(J_{\mathrm{PC}}=67 \mathrm{~Hz}\right)$ while the IR spectrum of 1 displays a complementary $\mathrm{C}=\mathrm{O}$ stretching band at $1648 \mathrm{~cm}^{-1}$.

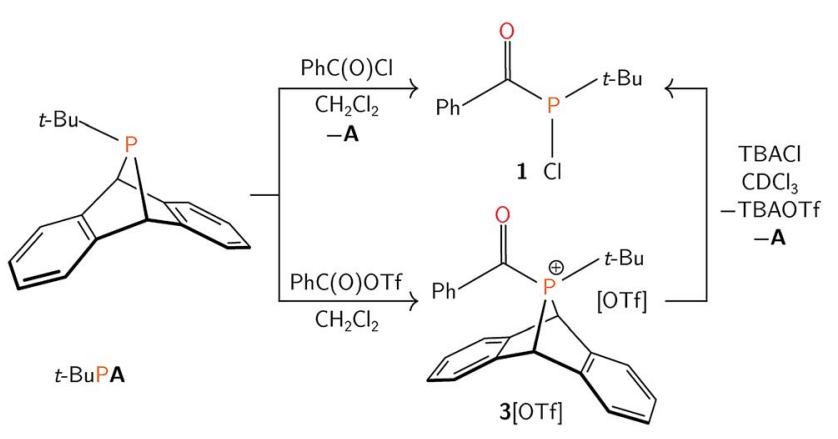

Scheme 1 Synthesis of 1 and 3[OTf]. 
Collectively, these data support the formulation of $\mathbf{1}$ as (tertbutylchlorophosphanyl)(phenyl)methanone, $\operatorname{PCl}(t-\mathrm{Bu})(\mathrm{C}(\mathrm{O}) \mathrm{Ph})$.

As 1 could not be isolated as single crystals suitable for structural analysis, a transition metal complex of this phosphine was prepared. Treatment of 1 with half an equivalent of $\left[\mathrm{Ru}(p \text {-cymene }) \mathrm{Cl}_{2}\right]_{2}$ in tetrahydrofuran led to the formation of coordination complex 2 . Layering the reaction mixture with pentane at $23{ }^{\circ} \mathrm{C}$ gave 2 as a red-orange crystalline material in $77 \%$ yield. Multinuclear NMR spectroscopy studies, in addition to a single crystal X-ray diffraction study confirmed the formulation of 2 as $\mathrm{Ru}(p$-cymene $) \mathrm{Cl}_{2}(\mathrm{PCl}(t-\mathrm{Bu})(\mathrm{C}(\mathrm{O}) \mathrm{Ph}))$ (Fig. 1). Racemic 2 crystallizes in the $P 2_{1} / c$ space group, and the solid state structure showed $\mathrm{C}-\mathrm{O}, \mathrm{P}-\mathrm{C}$, and $\mathrm{P}-\mathrm{Ru}$ bond lengths of 1.221(4), 1.875(4) and 2.3178(8) ̊ respectively, which are in line with the expected values. ${ }^{38} \mathrm{Ru}-\mathrm{P}$ binding of acylphosphines to ruthenium has been observed in the coordination chemistry of related P(III) ligands. ${ }^{39,40}$

Previous studies on thermal phosphinidene transfer have established that thermal loss of a phosphinidene does not occur when the R-group of an RPA compound is not $\pi$-donating. ${ }^{35}$ Therefore, the mechanism of acylphosphine formation is more likely to proceed associatively via nucleophilic attack by phosphorus at the electrophilic carbonyl group of benzoyl chloride. We envisioned that replacement of the chloride for a less nucleophilic anion may lead to the isolation of the putative cationic acylphosphonium intermediate. To this end, the reaction of equimolar solutions of $t$-BuPA and benzoyl triflate (PhC(O)OTf, OTf $\left.=\mathrm{CF}_{3} \mathrm{SO}_{3}{ }^{-}\right)^{41}$ led to the formation of 3[OTf] (Scheme 1) as a white powder in $75 \%$ yield. A singlet resonance is observed at $\delta 127 \mathrm{ppm}$ in the ${ }^{31} \mathrm{P}\left\{{ }^{1} \mathrm{H}\right\}$ NMR spectrum of 3 [OTf]. The ${ }^{13} \mathrm{C}\left\{{ }^{1} \mathrm{H}\right\}$ NMR spectrum of 3 [OTf] showed a diagnostic carbonyl resonance at $208 \mathrm{ppm}$ and the IR spectrum displayed a $\mathrm{C}=\mathrm{O}$ absorption peak at $1636 \mathrm{~cm}^{-1}$. These data are consistent with the formulation of $3[\mathrm{OTf}]$ as $[\mathrm{AP}(t-\mathrm{Bu})(\mathrm{C}(\mathrm{O}) \mathrm{Ph})][\mathrm{OTf}]$.

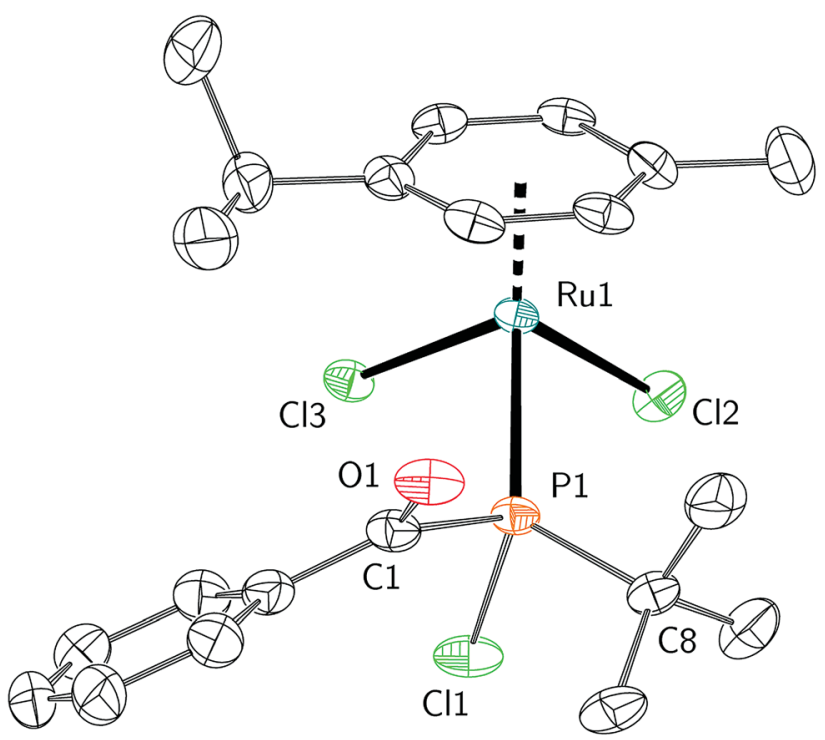

Fig. 1 Molecular structure of 2 with ellipsoids set at the $50 \%$ probability level and hydrogen atoms omitted for clarity.
Compound 3[OTf] decomposes slowly in solution at ambient temperature, yielding an anthracenyl(acyl)hydridophosphonium triflate salt as the major product (see ESI $\dagger$ ). Similar $\mathrm{C}-\mathrm{H}$ activation of arenes by phosphorus-containing electrophiles has been described for metal-stabilized phosphenium triflates. ${ }^{\mathbf{4 2 - 4 4}}$ Despite its instability in solution, 3 [OTf] can be stored in the solid state at $-35{ }^{\circ} \mathrm{C}$ for weeks without decomposition and purified by recrystallization from saturated dichloromethane/ pentane solutions, also at $-35{ }^{\circ} \mathrm{C}$. Treatment of 3 [OTf] with a chloride source (tetra- $n$-butylammonium chloride) in chloroform at $23{ }^{\circ} \mathrm{C}$ quantitatively generated 1, [TBA][OTf] and anthracene (Scheme 1). This reactivity is consistent with nucleophilic attack of the phosphonium center in 3 [OTf] by chloride, inducing reductive loss of anthracene.

The mechanism leading to the formation of $\mathbf{1}$ was probed via competition experiments involving the addition of two different para-substituted benzoyl chloride substrates in a $1: 1$ ratio to $t$ BuPA. The product ratio was determined by quantitative ${ }^{31} \mathrm{P}\left\{{ }^{1} \mathrm{H}\right\}$ NMR spectroscopy and a series of such experiments is summarised in the Hammett plot (Fig. 2). A small negative value for $\rho$ of -2.36 is consistent with build-up of positive charge in the transition state. ${ }^{45}$ This is particularly evident for electron withdrawing groups, such as $\mathrm{CF}_{3}$, where the reaction is accelerated compared to electron rich para-substituted benzoyl chlorides. These electronic effects are further evidence of phosphine attack at the electrophilic carbon atom of the acylphosphine functional group in the rate limiting step of the reaction.

Quantum chemical calculations were employed to study the formation of 1. These were performed using ORCA 4.0.0.2 ${ }^{46}$ at the B3LYP/Def2-TZVP level of theory and the results are summarised in Fig. 3. According to our calculations, initial nucleophilic attack of $t$-BuPA on benzoyl chloride proceeds with an activation barrier of $+17.9 \mathrm{kcal} \mathrm{mol}^{-1} \mathbf{T S 1}$, in which the phosphorus atom occupies a tetrahedral environment, leads to an intermediate comprising a phosphonium and chloride ion-pair,
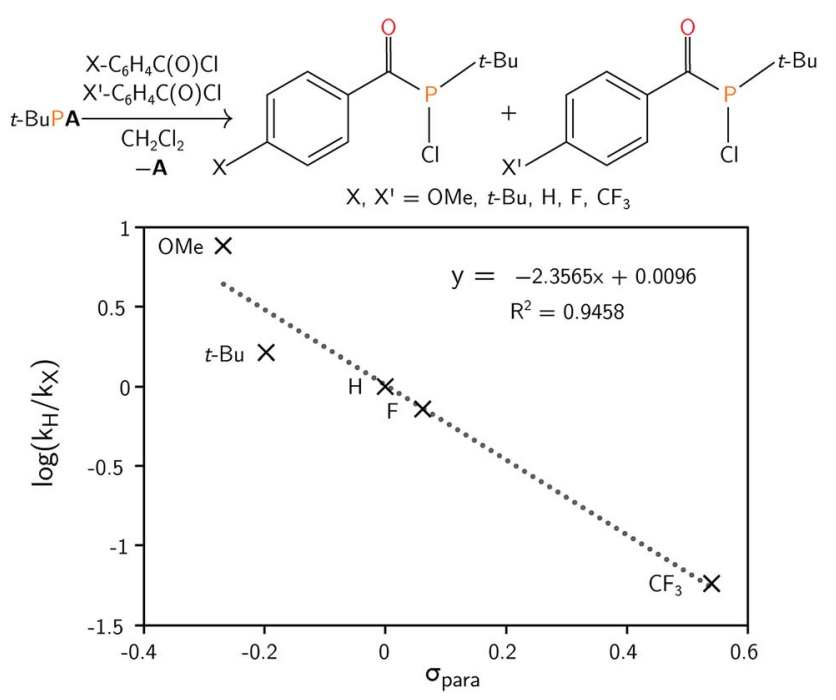

Fig. 2 (Top) Preparation of acyl(chloro)phosphines starting from $t$ BuPA and para-substituted benzoyl chlorides. (Bottom) Hammett plot for the reaction, obtained by competition experiments. 


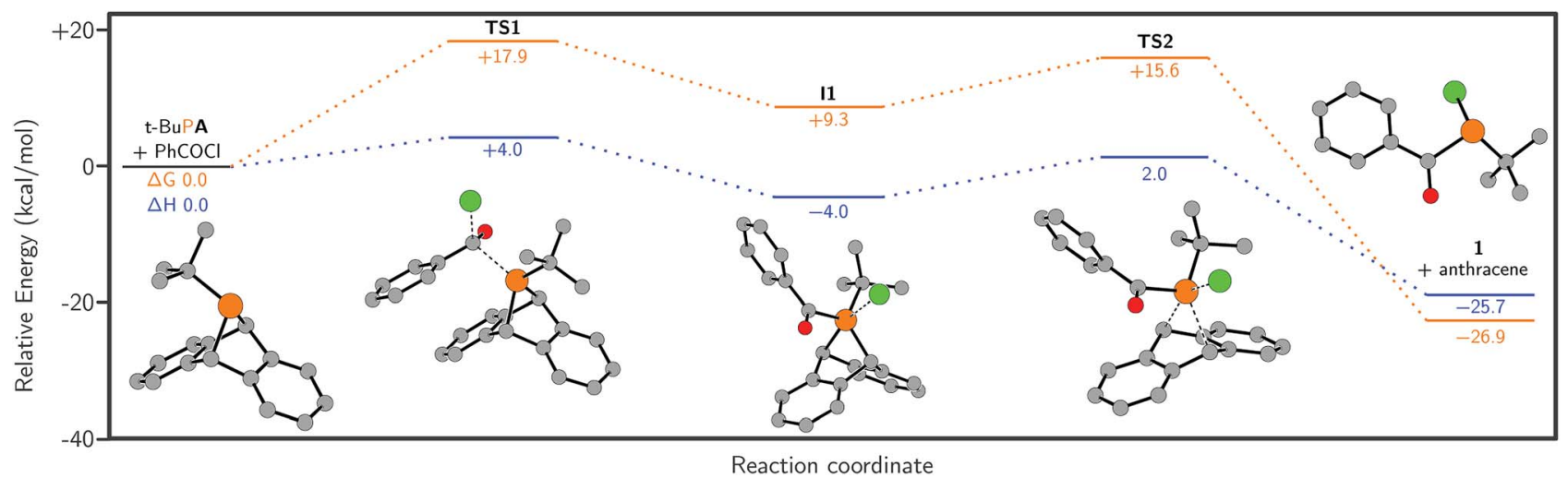

Fig. 3 Calculated lowest energy pathway for the reaction of $t$-BuPA with benzoyl chloride, at the B3LYP/Def2-TZVP level of theory (see ESI $\uparrow$ for full computational details). $\Delta G$ is shown in orange and $\Delta H$ is shown in blue. Hydrogen atoms are omitted for clarity.

I1. The distance between the phosphorus and chlorine atoms is $2.55 \AA$ which is significantly longer than the sum of the singlebond covalent radii, $2.10 \AA^{38} .^{38}$ However, the phosphorus center features a trigonal bipyramidal structure instead of the ideal tetragonal coordination sphere of a 4-coordinate phosphonium species, suggestive of a strong interaction between the phosphonium centre and chloride. A second transition state in the reaction pathway TS2 was located, which corresponds to formation of a $\mathrm{P}-\mathrm{Cl}$ bond and concomitant loss of anthracene to give 1. TS2 had a relative Gibbs free energy of $+15.6 \mathrm{kcal} \mathrm{mol}^{-1}$, which is lower than the Gibbs free energy for TS1. The loss of anthracene in TS2 is highly concerted and appears to proceed by a cheletropic extrusion pathway. This type of formal reductive elimination from $\lambda-5$ phosphoranes to give a phosphorus(III) product has previously been described in the literature. ${ }^{47-50}$ Finally, we investigated the possibility of a phosphenium chloride salt intermediate (I2, see ESI $\dagger$ ), which would arise from loss of anthracene from cation $\mathbf{3}$ and is the formal reverse of the McCormack reaction. ${ }^{49-51}$ We found the relative Gibbs free energy of intermediate $\mathbf{I} 2$ to be $65.0 \mathrm{kcal} \mathrm{mol}^{-1}$ which is significantly higher than either TS1 of TS2, ostensibly ruling it out as an intermediate in the reaction mechanism (see ESI $\dagger$ ).

The higher Gibbs free energy of the first transition state compared to the second is consistent with experiment, where a phosphonium intermediate is not observed when benzoyl chloride is used as the acylating reagent. Thus it is indicated that, when switching from chloride to triflate, there is a change in the rate determining step from TS1 to TS2, which are in proximity (17.9 and $15.6 \mathrm{kcal} \mathrm{mol}^{-1}$, respectively) as determined by DFT calculations.

Efforts to further derivatise 1 were undertaken by reduction of the $\mathrm{P}-\mathrm{Cl}$ bond. Treatment of compound 1 with 2 equivalents of freshly-prepared sodium naphthalenide ${ }^{52}$ led to the formation of a new species with concomitant formation of naphthalene and sodium chloride (Scheme 2). Addition of 15-crown-5 to the reaction mixture led to the isolation of $[\mathrm{Na}(15-$ crown-5) $] 4$ as a crystalline orange powder in $49 \%$ yield. The connectivity of anion 4 as $[\mathrm{OC}(\mathrm{Ph}) \mathrm{P} t \text {-Bu }]^{-}$was confirmed by a single crystal $\mathrm{X}$ ray diffraction experiment (Fig. 4). In the solid state, the $\mathrm{P}-\mathrm{C}$ and $\mathrm{C}-\mathrm{O}$ bond lengths are 1.756(2) and 1.271(2) A, respectively.
The short $\mathrm{C}-\mathrm{P}$ bond and long $\mathrm{C}-\mathrm{O}$ bond are consistent with delocalization of electron density from a phosphide lone pair into the $\pi^{*}(\mathrm{C}=\mathrm{O})$ orbital.

To quantify the degree of electron delocalization over the acylphosphide functional group, the electronic structure was evaluated using natural bond orbital (NBO) methods. ${ }^{53}$ Natural resonance theory (NRT) analysis, implemented within the NBO package, showed that the primary resonance structure (4a, Fig. 5) had a contribution of 39\%. A second resonance structure, containing a carbon-phosphorus double bond and carbonoxygen single bond (4b, Fig. 5), closely followed with a contribution of $33 \%$, while the remaining resonance structures each had less than $2 \%$ weight. The $\mathrm{C}-\mathrm{O}$ and $\mathrm{C}-\mathrm{P}$ natural bond orders were remarkably similar at 1.51 and 1.49 , respectively. The high degree of delocalization of the phosphide lone pair into the carbonyl unit seems to be a result of the anionic charge and of having two lone pairs at $\mathrm{P}$, one of which is higher in energy and has more $\mathrm{p}$-character and is thus more prone to delocalization, since for neutral acylphosphine-containing molecules, minimal delocalization has been observed..$^{5,55}$

The combination of $[\mathrm{Na}(15-$ crown-5) $] 4$ and $\mathrm{AdC}(\mathrm{O}) \mathrm{Cl}(\mathrm{Ad}=1$ adamantyl) in tetrahydrofuran generated $\mathbf{5}$, which was isolated as a crystalline yellow solid in $55 \%$ yield (Scheme 2 ). In the ${ }^{31} \mathrm{P}$ $\left\{{ }^{1} \mathrm{H}\right\}$ NMR spectrum of 5 , a singlet resonance is observed at $\delta 37 \mathrm{ppm}$. Two diagnostic doublet resonances are observed in the downfield region of the ${ }^{13} \mathrm{C}\left\{{ }^{1} \mathrm{H}\right\} \mathrm{NMR}$ spectrum at $\delta 225\left(J_{\mathrm{PC}}\right.$ $=50 \mathrm{~Hz})$ and $214 \mathrm{ppm}\left(J_{\mathrm{PC}}=46 \mathrm{~Hz}\right)$, which are assigned to the two acyl carbon atoms. The IR spectrum of 5 shows two $\mathrm{C}=\mathrm{O}$ absorption peaks at 1665 and $1629 \mathrm{~cm}^{-1}$. These spectroscopic data inform our formulation of $\mathbf{5}$ as $\mathrm{OC}(\mathrm{Ph}) \mathrm{P}(\mathrm{C}(\mathrm{O}) \mathrm{Ad}) t-\mathrm{Bu}$. Single crystals of $\mathbf{5}$ were grown from a concentrated pentane

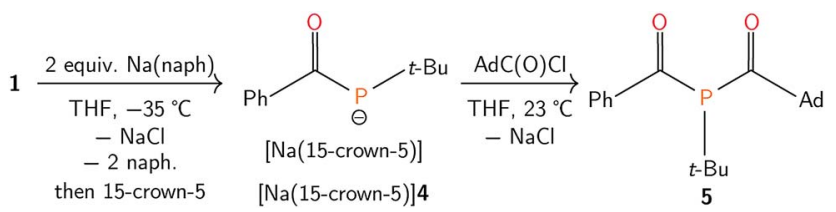

Scheme 2 Synthesis of [Na(15-crown-5)]4 and 5. 


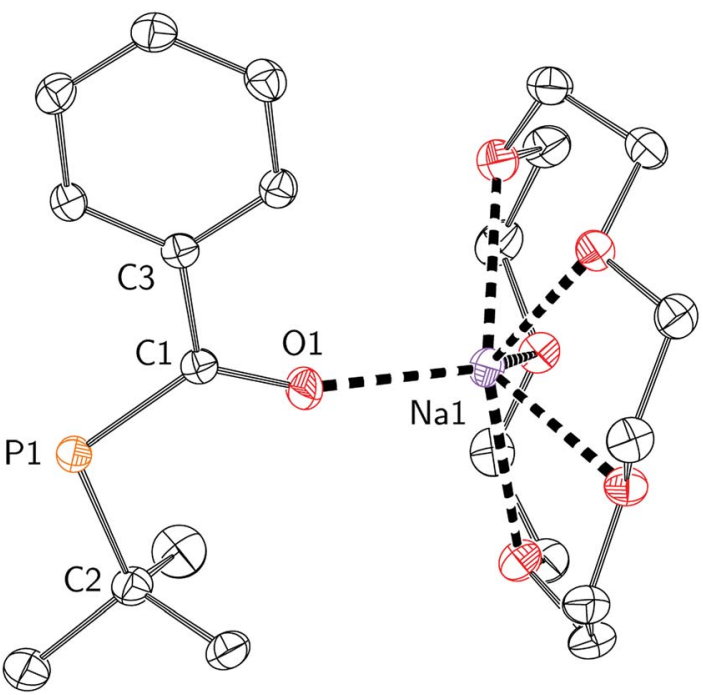

Fig. 4 Molecular structure of [Na(15-crown-5)]4 with ellipsoids set at the $50 \%$ probability level and hydrogen atoms omitted for clarity.<smiles>CCCCCP(C([O-])=PC(C)(C)C)c1ccccc1</smiles>

Fig. 5 Leading resonance structures of anion 4, as determined by Natural Resonance Theory (NRT), implemented within the Natural Bond Orbital (NBO) package.

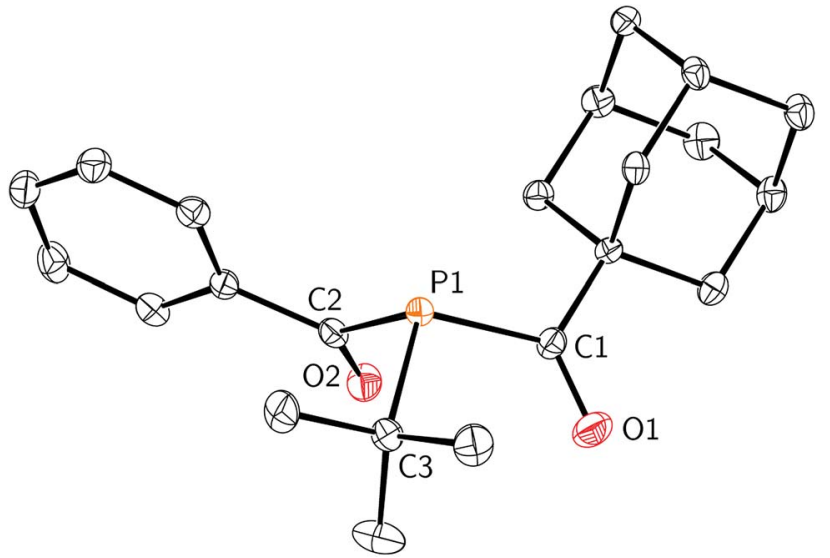

Fig. 6 Molecular structure of $(R)-5$ with ellipsoids set at the $50 \%$ probability level and hydrogen atoms omitted for clarity. P1-C1, C1$\mathrm{O} 1, \mathrm{P} 1-\mathrm{C} 2$ and $\mathrm{C} 2-\mathrm{O} 2$ bond lengths are 1.209(4), 1.902(3), 1.212(4) and $1.888(3) \AA$, respectively.

solution and analyzed by an X-ray diffraction study, which featured 5 as a single $(R)$-enantiomer (see ESI $\dagger$ ) in the chiral space group $P 2_{1}$ (Fig. 6).

The formation of 5 from [Na(15-crown-5)]4 provides an approach for preparing dissymmetric bis(acyl)phosphines. ${ }^{56}$ Interestingly, a previous report of a $\left(\mathrm{W}(\mathrm{CO})_{5}\right)$ P-protected acylphosphide anion describes $\mathrm{C}-\mathrm{O}$ instead of $\mathrm{C}-\mathrm{P}$ bond formation upon treatment with an acyl chloride, to give an ester-containing phosphaalkene. ${ }^{57}$

In summary, we have described a novel reaction of $t$-BuPA with acyl chlorides to give acyl(chloro)phosphine-containing products, which were not accessible previously. ${ }^{36,37}$ Experimental mechanistic studies agree well with computational insights, and clearly demonstrate the presence of an intermediate acylphosphonium species. The acyl(chloro)phosphine functional group can be reduced to the corresponding acylphosphide anion, which reacts further with an acyl chloride to provide access to a dissymmetric bis(acyl)phosphine. Other synthetic pathways to related acylphosphine derivatives are the subject of on-going investigations.

\section{Conflicts of interest}

There are no conflicts to declare.

\section{Acknowledgements}

The authors acknowledge computational support from the Massachusetts Green High-Performance Computing Center. We thank the National Science Foundation (NSF-CHE-1664799) for financial support of this research. D. W. S. is grateful for the award of an NSERC Canada Research Chair and a visiting Einstein Professorship at TU Berlin (2016-2019). K. M. S. acknowledges the support of an NSERC PGS-D award and the University of Toronto Department of Chemistry for a Special Opportunity Graduate Travel Fellowship. Dr Eric Arndt of Formlabs is thanked for stimulating discussion. Dr Peter Müller is gratefully thanked for his assistance with crystallographic studies.

\section{Notes and references}

1 L. Gonsalvi and M. Peruzzini, Angew. Chem., Int. Ed., 2012, 51, 7895-7897.

2 K. Dietliker, A compilation of photoinitiators: commercially available for UV today, SITA Technology Ltd, Edinburgh, London, 2002.

3 K. Dietliker, T. Jung, J. Benkhoff, H. Kura, A. Matsumoto, H. Oka, D. Hristova, G. Gescheidt and G. Rist, Macromol. Symp., 2004, 217, 77-98.

4 E. Schrader, Doctoral thesis, ETH Zürich, 2018.

5 P. Lechtken, I. Buethe, M. Jacobi and W. Trimborn, US4298738A, 1981.

6 P. Lechtken, B. Bronstert, G. Hoffmann, R. Vyvial and J. Lynch, US4292152A, 1981.

7 P. Lechtken, I. Buethe and A. Hesse, US4324744A, 1982.

8 A. Henne, A. Hesse, M. Jacobi, G. Schornick, R. Vyvial and K. Holoch, US4447520A, 1984.

9 C.-T. Huang, P. D. Hammesfahr and S. R. Jefferies, US5367002A, 1994.

10 H. Grützmacher, T. Ott and K. Dietliker, WO2011003772A1, 2011. 
11 N. Karim, T. D. Jones, K. M. Lewandowski, B. D. Craig, S. B. Mitra and J. Yang, EP2073782B1, 2011.

12 S. Stelzig, J. Klee, A. Facher and C. Weber, EP2497454A1, 2012.

13 A. A. Guimont, C. Li, X. Zhou, H. S. Bui and J.-T. Simonnet, US9636293B2, 2017.

14 X. Zhou, C. Li, H. S. Bui and J.-T. Simonnet, US9801803B2, 2017.

15 G. Becker, Z. Anorg. Allg. Chem., 1981, 480, 38-48.

16 G. Becker, M. Rössler and W. Uhl, Z. Anorg. Allg. Chem., 1981, 473, 7-19.

17 G. Becker, Z. Anorg. Allg. Chem., 1981, 480, 21-37.

18 S. A. Kosarev and S. J. Collier, Tris(trimethylsilyl)phosphine, in Encyclopedia of Reagents for Organic Synthesis, John Wiley \& Sons, 2011.

19 D. S. Bohle, G. R. Clark, C. E. F. Rickard and W. Roper, J. Organomet. Chem., 1988, 353, 355-381.

20 D. S. Bohle, G. R. Clark, C. E. F. Rickard and W. R. Roper, J. Organomet. Chem., 1990, 393, 243-285.

21 J.-J. Brunet, A. Capperucci, R. Chauvin and B. Donnadieu, J. Organomet. Chem., 1997, 533, 79-81.

22 J.-J. Brunet, R. Chauvin, B. Donnadieu and E. Thepaut, J. Organomet. Chem., 1999, 579, 198-205.

23 A. Antiñolo, S. Gacía-Yuste, A. Otero, R. Reguillo-Carmona and M. T. Tercero-Morales, C. R. Chim., 2010, 13, 929-934.

24 C. L. Liotta, M. L. McLaughlin and B. A. O'Brien, Tetrahedron Lett., 1984, 25, 1249-1252.

25 C. L. Liotta, M. L. McLaughlin, D. G. Van Derveer and B. A. O'Brien, Tetrahedron Lett., 1984, 25, 1665-1668.

26 G. Becker, W. Schwarz, N. Seidler and M. Westerhausen, Z. Anorg. Allg. Chem., 1992, 612, 72-82.

27 B. A. Trofimov, S. N. Arbuzova and N. K. Gusarova, Russ. Chem. Rev., 1999, 68, 215-228.

28 J. Wang, G. Siqueira, G. Müller, D. Rentsch, A. Huch, P. Tingaut, J. Levalois-Grützmacher and H. Grützmacher, Chem. Commun., 2016, 52, 2823-2826.

29 A. Huber, A. Kuschel, T. Ott, G. Santiso-Quinones, D. Stein, J. Bräuer, R. Kissner, F. Krumeich, H. Schönberg, J. Levalois-Grützmacher and H. Grützmacher, Angew. Chem., Int. Ed., 2012, 51, 4648-4652.

30 A. Eibel, M. Schmallegger, M. Zalibera, A. Huber, Y. Bürkl, H. Grützmacher and G. Gescheidt, Eur. J. Inorg. Chem., 2017, 2017, 2469-2478.

31 K. X. Bhattacharyya, S. Dreyfuss, N. Saffon-Merceron and N. Mézailles, Chem. Commun., 2016, 52, 5179-5182.

32 J. M. Goicoechea and H. Grützmacher, Angew. Chem., Int. Ed., 2018, 57, 16968-16994.

33 J.-P. Wolf and G. Hug, US20050245768A1, 2005.
34 A. Velian and C. C. Cummins, J. Am. Chem. Soc., 2012, 134, 13978-13981.

35 W. J. Transue, A. Velian, M. Nava, C. García-Iriepa, M. Temprado and C. C. Cummins, J. Am. Chem. Soc., 2017, 139, 10822-10831.

36 Y. A. Veits, M. V. Filippov, A. A. Borisenko and V. L. Foss, $Z h$. Obshch. Khim., 1991, 61, 108-113.

37 Y. A. Veits, E. G. Neganova, M. V. Filippov, A. A. Borisenko and V. L. Foss, Zh. Obshch. Khim., 1991, 61, 114-118.

38 P. Pyykkö and M. Atsumi, Chem.-Eur. J., 2009, 15, 186-197.

39 S. Gowrisankar, H. Neumann, A. Spannenberg and M. Beller, Organometallics, 2014, 33, 94-99.

40 K. M. Szkop, A. R. Jupp and D. W. Stephan, J. Am. Chem. Soc., 2018, 140, 12751-12755.

41 L. Brown and M. Koreeda, J. Org. Chem., 1984, 49, 3875-3880.

42 A. Jayaraman and B. T. Sterenberg, Organometallics, 2016, 35, 2367-2377.

43 A. Jayaraman, S. Nilewar, T. V. Jacob and B. T. Sterenberg, ACS Omega, 2017, 2, 7849-7861.

44 S. Nilewar, A. Jayaraman and B. T. Sterenberg, Organometallics, 2018, 37, 4699-4710.

45 E. V. Anslyn and D. A. Dougherty, Modern Physical Organic Chemistry, University Science, Sausalito, CA, 2006.

46 F. Neese, Wiley Interdiscip. Rev.: Comput. Mol. Sci., 2012, 2, 73-78.

47 D. B. Denney, D. Z. Denney, C. D. Hall and K. L. Marsi, J. Am. Chem. Soc., 1972, 94, 245-249.

48 K. A. Mesch and L. D. Quin, Tetrahedron Lett., 1980, 21, 47914794.

49 T. Kee, in Phosphorus-Carbon Heterocyclic Chemistry, ed. F. Mathey, Elsevier Science Ltd, Oxford, 2001, pp. 195-218.

50 K. D. Reichl and A. T. Radosevich, Chem. Commun., 2014, 50, 9302-9305.

51 A. H. Cowley, R. A. Kemp, J. G. Lasch, N. C. Norman and C. A. Stewart, J. Am. Chem. Soc., 1983, 105, 7444-7445.

52 N. G. Connelly and W. E. Geiger, Chem. Rev., 1996, 96, 877910.

53 F. Weinhold and C. R. Landis, Valency and bonding: a natural bond orbital donor-acceptor perspective, Cambridge University Press, Cambridge, UK; New York, 2005.

54 A. R. Jupp and J. M. Goicoechea, J. Am. Chem. Soc., 2013, 135, 19131-19134.

55 M. B. Geeson, A. R. Jupp, J. E. McGrady and J. M. Goicoechea, Chem. Commun., 2014, 50, 12281-12284.

56 R. H. Sommerlade, S. Boulmaâz, J.-P. Wolf, J. Geier, H. Grützmacher, M. Scherer, H. Schönberg, D. Stein, P. Murer and S. Burkhardt, WO2005014605A1, 2005.

57 V. Nesterov, L. Duan, G. Schnakenburg and R. Streubel, Eur. J. Inorg. Chem., 2011, 2011, 567-572. 